\title{
Glucosinolates in Erysimum hieracifolium L.; Three New, Naturally Occurring Glucosinolates
}

\author{
A NDERS K J FR and A NGELIGA SCHUSTER \\ Department of Organic Chemistry, Technical University of Denmark, \\ DK-2800 Lyngby, Denmark
}

\begin{abstract}
Seed extracts of Erysimum hieracifolium L. (Cruciferae) contain at least five glucosinolates. Upon enzymic hydrolysis, they produce a series of isothiocyanates which can be separated chromatographically.

By application of chemical and spectroscopic methods the isothiocyanates are identified as: (1) 5-methylthiopentyl, (2) (R)-5-methylsulphinylpentyl, (3) 3-hydroxy-5-methylthiopentyl, (4) 3-hydroxy-5methylsulphinylpentyl, and (5) 3-hydroxy-5-methylsulphonylpentyl isothiocyanate. Of these, (3), (4), and (5) undergo facile spontaneous or base-induced cyclizations to the corresponding, chiral 6-substituted tetrahydro-1,3-oxazine-2-thiones.

Determination of the absolute configuration of the naturally derived isothiocyanates (3), (4), and (5) is a subject of present studies.

The occurrence of 5-methylthiopentylglucosinolate, and its higher oxidized analogues, is new to the genus Erysimum. The possible taxonomic significance hereof is briefly discussed.
\end{abstract}

$\mathrm{T}$

he genus Erysimum (Cruciferae) is one of great taxonomic complexity, even when limited to taxa indigenous to Northern and Central Europe. For this and other reasons, we considered the genus inviting for phytochemical studies and have subjected seeds of a number of Erysimum species to a detailed analysis for their contents of glucosinolates (I). The results will appear in a separate communication. ${ }^{1}$

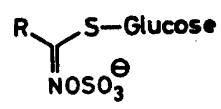

(1)

In the course of these studies, however, seed extracts of $E$. hieracifolium L.* attracted our special interest, due to their complex and unusual

* The seed employed was produced by large scale cultivation in the Botanic Garden of the University of Copenhagen. Herbarium vouchers of the plants are deposited in the Botanic Museum of the University of Copenhagen.

Acta Chem. Scand. 24 (1970) No. 5 
glucosinolate patterns as revealed by routine paper-chromatographic analyses. Detailed investigations disclosed the presence in the extracts of a number of glucosinolates not previously encountered in Nature. We report the results here.

\section{RESULTS}

Paper chromatography, in two solvent systems (see Experimental), of a methanolic seed extract of $E$. hieracifolium revealed its contents of several glucosinolates. In order to obtain information about their chemical character, a purified extract of a larger seed sample $(300 \mathrm{~g})$ was subjected to enzymatic hydrolysis with a myrosinase preparation. The chloroform-soluble products formed in the enzymatic reaction $(2.1 \mathrm{~g})$ were fractionated by column chromatography on silica gel. Five main fractions, numbered $1-5$ according to the order in which they appeared from the column, were collected and separately studied.

Fraction 1. Cautious evaporation of an aliquot of fraction 1 left an oil which by combined gas chromatography/mass spectrometry was identified as 5-methylthiopentyl isothiocyanate (II), a compound previously encountered as a product formed by enzymic hydrolysis of a glucosinolate in seeds of the crucifer Berteroa incana (L.) DC., ${ }^{2}$ but most likely present also in several

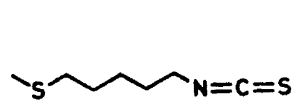

(II)

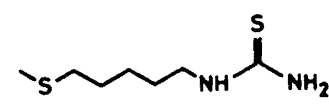

(III)

species of the genera Alyssum ${ }^{3}$ and Lunaria. ${ }^{2}$ In order to substantiate the identification of (II), another aliquot was converted into the corresponding thiourea on reaction with ammonia. Critical comparison of the latter with an authentic specimen ${ }^{2}$ proved it to be 1-(5-methylthiopentyl)-thiourea (III).

Fraction 2. This fraction was divided into two parts. (i) One was treated with methanolic ammonia, and the product mixture $(300 \mathrm{mg})$ was separated by chromatography on silicagel. Two major products, A and B, were isolated in homogeneous form.

Compound A, m.p. 58-59 , was strongly levorotatory and possessed the composition $\mathrm{C}_{7} \mathrm{H}_{13} \mathrm{NOS}_{2}$. This, together with its formation and spectroscopic properties (UV, IR, NMR, and mass spectra), strongly indicated that its structure was (IV), yet with so far unknown absolute configuration.

Compound B, m.p. $71-72^{\circ}$, with the composition $\mathrm{C}_{7} \mathrm{H}_{16} \mathrm{~N}_{2} \mathrm{OS}_{2}$, was moderately levorotatory and possessed chemical and spectroscopical properties in keeping with structure (V), again with as yet unknown chirality.

(ii) The remaining part of fraction 2 was treated with triethylamine at room temperature, resulting in slow formation of (IV).

The results strongly indicate that the initial product from the enzymic hydrolysis giving rise to the formation of (IV) and (V) is a chiral 3-hydroxy- 


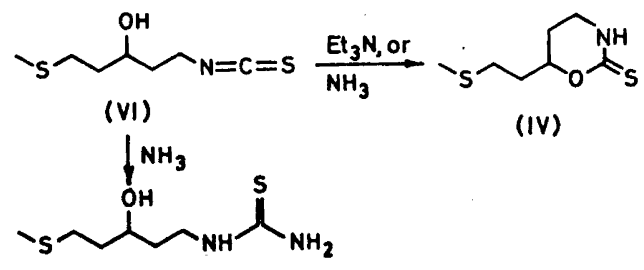

(v)

5-methylthiopentyl isothiocyanate (VI). In base-catalyzed reactions $\left(\mathrm{Et}_{3} \mathrm{~N}\right)$, 3-hydroxyalkyl isothiocyanates undergo cyclizations to tetrahydro-1,3-oxazine2-thiones, as previously established, ${ }^{4}$ explaining, in the present case, the formation of (IV) in reaction (ii). In the ammonia reaction (i), two competitive reactions take place, one leading, as expected, to the thiourea (V), and another affording the cyclic derivative (IV).

Fraction 3. The oily residue $(155 \mathrm{mg})$ from fraction 3 possessed properties characteristic for a sulphoxide-isothiocyanate. For further characterization, it was converted into a crystalline phenylthiourea upon reaction with aniline. Analytical and spectroscopical data indicated that the structure of the latter was (VII), confirmed upon critical comparison with an authentic specimen * of $(R)$ 1-(5-methylsulphinylpentyl)-3-phenylthiourea. ${ }^{3}$ Hence, the enzymic hydrolysis product in fraction 3 is $(R)-5$-methylsulphinylpentyl isothiocyanate (VIII), previously encountered as a glucosinolate hydrolysis product in seed extracts of various species of Alyssum. ${ }^{3}$<smiles>C[As](C)(C)O[AsH2]</smiles>

(VII)<smiles>CS(=O)(=O)O[Na]</smiles>

(VIII)

Fraction 4. This fraction $(270 \mathrm{mg}$ ) contained a crystalline, dextrorotatory isothiocyanate, which according to spectroscopic data, contained a sulphone grouping. On treatment with $\mathrm{Et}_{3} \mathrm{~N}$, or heating to $110^{\circ}$, the isothiocyanate cyclized to a chirally still undefined, levorotatory tetrahydro-1,3-oxazine-2thione possessing the structure $(\mathrm{X})$. Consequently, the isothiocyanate representing the initial enzymic hydrolysis product is 3-hydroxy-5-methylsulphonylpentyl isothiocyanate (IX), the stereochemistry of which has not yet been established.

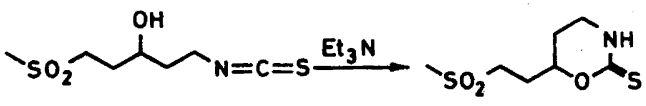

(IX)

(x)

* The absolute configuration of (VII) has been unequivocally determined by ORD comparison with $(R)$ I-(3-methylsulphinylpropyl)-3-phenylthiourea, the structure of which was established by X-ray analysis.

Acta Chem. Scand. 24 (1970) No. 5 
Fraction 5. From this last fraction another levorotatory tetrahydro-1,3oxazine-2-thione was obtained, subsequent to triethylamine treatment and chromatographic purification. On the basis of composition and spectroscopic properties, it was assigned the structure (XII), undoubtedly resulting from cyclization of an initially formed 3-hydroxy-5-methylsulphinylpentyl isothiocyanate (XI).

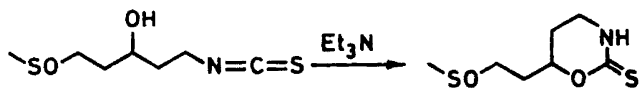

$(x \mid)$

(XII)

\section{DISCUSSION}

On the reasonable assumption that the various isothiocyanates and cyclized derivatives discussed above arise by enzymic hydrolysis of glucosinolates in the usual fashion ( $c f$. Ref. 6), it is concluded that seed extracts of $E$. hieracifolium L. contain the glucosinolates (XIII)-(XVII), three of which, viz. (XIV), (XVI), and (XVII), are new as natural products.

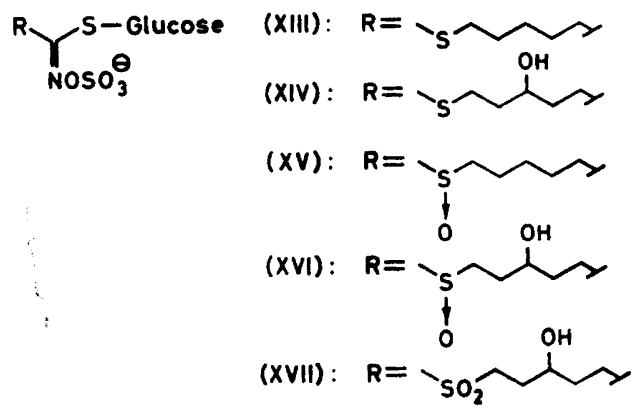

The fact that the glucosinolates (XIII) - (XVII) represent nothing more than oxidation stage variants of the 5-methylthiopentylglucosinolate sidechain (XIII) is noteworthy inasmuch as the methylthiopentyl side-chain is new for the genus Erysimum. Seeds of several species previously studied have typically contained glucosinolates with the side-chains $\mathrm{R}=\mathrm{CH}_{3} \mathrm{SO}_{x}\left(\mathrm{CH}_{2}\right)_{y}$-, $\left(x=0,1,2 ; y=3\right.$ and 4) ${ }^{1,7,8}$ Occasionally, other side-chains, such as $\mathrm{MeOOC}\left(\mathrm{CH}_{2}\right)_{3}-,,^{9,10}(p)-\mathrm{OHC}_{6} \mathrm{H}_{4} \mathrm{CH}_{2}-{ }_{1}^{1}$ or $\mathrm{CH}_{2}=\mathrm{CHCH}_{2}-{ }^{1}$ have been encountered in species of the genus Erysimum. The question therefore arises as to the possible significance of chemical characters, such as the glucosinolate composition, for taxonomic purposes within the present group. The genus Erysimum constitutes a very complex and polymorphous group of taxa, the classification of which poses great difficulties. This is reflected in an extensive and rather controversial botanical literature on the identity and affinity of the numerous Erysimum species, including, inter alia, a number of cytotaxonomic studies (cf., e.g., Ref. 11). The observed pattern of glucosinolates in 
E. hieracifolium L. is unique within a long series of Erysimum species studied so far in this laboratory. The possible taxonomic significance of this observation will be discussed elsewhere in another context.

It would appear likely that the glucosinolates (XIV), (XVI), and (XVII) possessed the same chirality at the carbinol center in the side-chain, resulting, of course, in identical stereochemistry of the derived isothiocyanates and their cyclized counterparts. * Likewise, it would be expected that the sulphoxide-glucosinolate (XVI) possessed the same configuration, viz. $(R)$, at the chiral sulphoxide center as that prevailing in the co-occurring, nonhydroxylated analogue. ${ }^{5}$ Determination of the absolute configurations around the chiral $\mathrm{C}$ - and S-centers in the side-chains of the glucosinolates (XIV), $(\mathrm{XVI})$, and (XVII) is presently a matter of study in this laboratory.

\section{EXPERIMENTAL}

Melting points are uncorrected and determined in an electrically heated bath. Analytical specimens are dried in vacuo over calcium chloride at room temperature before analysis. Paper chromatography is performed on Schleicher \& Schüll 2043 b paper. Column chromatography is carried out on Merck $0.05-0.2 \mathrm{~mm}$ silicagel. Rotations are measured on a Perkin-Elmer 141 photoelectric polarimeter. UV-spectra are measured on a Perkin-Elmer 402 instrument, IR spectra on a Perkin-Elmer Infracord. NMR. spectra are routinely recorded on a Varian A 60 instrument, and mass spectra on a Perkin-Elmer 270 instrument equipped with a gas chromatograph as well as a solid inlet; ionization potential: $70 \mathrm{eV}$.

Paperchromatographic analysis. Ground seeds $(5 \mathrm{~g})$ of Erysimum hieracifolium L. were extracted with hot $70 \% \mathrm{MeOH}$, and the extract was utilized for descending paper chromatography in the solvent systems: (i) butanol:ethanol:water (4:1:4), and (ii) butanol: pyridine:water $(6: 4: 3)$. The chromatograms were sprayed with silver nitrate, whereby the glucosinolates appeared as grey-brown spots. In (i), major spots were noted with $R_{B}$-values (i.e. $R_{F}$-values relative to that of benzylglucosinolate $\left(\mathrm{I}, \mathrm{R}=\mathrm{C}_{6} \mathrm{H}_{5} \mathrm{CH}_{2}\right.$ )) of $0.18,0.46,0.72$, and $c a$. 1.0 ; in (ii), strong spots were visible with $R_{B}$-values of 0.23 , 0.45 , and $c a$. 1.0. Several of the spots showed signs of being of multicomponent composition.

Enzymic hydrolysis and TLC. An aliquot of the above solution was freed of methanol and subjected to enzymic hydrolysis with a myrosinase preparation. The solution was then extracted with chloroform, and a few $\mu$ l of the concentrated solution were applied to the corner of a chromatographic silica gel plate. The plate was developed in $\mathrm{CHCl}_{3}$ :EtOH (95:5), air-dried, and kept in an $\mathrm{NH}_{3}$-atmosphere overnight. It was then developed in the same solvent after turning the plate $90^{\circ}$. Spraying with Grote's reagent revealed the presence of at least five thioureas as distinctly blue spots. Three of these were accompanied by more lipophilic products, yielding pale blue colours, quite characteristic for cyclized 2- or 3-hydroxy-substituted alkyl isothiocyanates.

Extraction, enzymic hydrolysis, and separation of products. Seeds of $E$. hieracifolium $(300 \mathrm{~g})$ were finely ground and defatted by extraction with two $600 \mathrm{ml}$-portions of petroleum ether. The seed powder $(210 \mathrm{~g})$ was extracted three times with 1.0 l-portions of refluxing $70 \%$ methanol. The extracts were combined, and all methanol was removed by distillation in vacuo. The aqueous residue was diluted to 11 with water, and a $20 \%$ lead acetate solution was added to precipitate impurities. After filtration, $\mathrm{Na}_{2} \mathrm{HPO}_{4}-$ solution was added to remove excess lead ions. The filtrate was brought to $\mathrm{pH} 6.8$, and a myrosinase solution $(10 \mathrm{ml})$, and a trace of ascorbic acid, were added. After $6 \mathrm{~h}$ at room temperature, the reaction mixture was extracted five times with $50 \mathrm{ml}$ portions of

* Added in proof: CD-measurements have indeed confirmed identical chirality of (IV) and (X).

Acta Chem. Scand. 24 (1970) No. 5 
chloroform. The combined extracts were dried overnight over anhydrous $\mathrm{Na}_{2} \mathrm{SO}_{4}$ and evaporated to dryness. The residue $(2.1 \mathrm{~g})$ was redissolved in a small volume of chloroform and transferred to a column of silicagel $(60 \mathrm{~g})$, deactivated with $15 \%$ of water.

The chromatographic development was performed with chloroform $(350 \mathrm{ml})$, followed by $350 \mathrm{ml}$ portions of chloroform containing 1, 2, 4, and $6 \%$ of ethanol. $20 \mathrm{ml}$ fractions were collected.

Fraction 1. This consisted of the first $60 \mathrm{ml}$ of eluate emerging from the column. An aliquot $(4 \mathrm{ml})$ was concentrated on a watchglass. The residue was dissolved in a few drops of ether and injected into a gas-chromatograph combined with a mass spectrometer. One predominant peak appeared, the mass spectrum of which was indistinguishable from that of an authentic specimen of 5 -methylthiopentyl isothiocyanate (II).12

The remaining solution was treated with methanolic ammonia (25 ml) overnight. The solution was concentrated to dryness, and the residue was recrystallized from ethyl acetate to give a product, which, according to UV-, IR-, and mass-spectrometry, was identical with 1-(5-methylthiopentyl)-thiourea (III). ${ }^{2}$

Fraction. 2. The next $360 \mathrm{ml}$ of the column eluate was evaporated to give about $500 \mathrm{mg}$ of oily material, which was divided into (i) a $300 \mathrm{mg}$ and (ii) a $200 \mathrm{mg}$ portion. These were processed separately as described in the following.

(i) The oily product (300 $\mathrm{mg}$ ) was dissolved in methanolic ammonia $(25 \mathrm{ml}$ ) and set aside for $6 \mathrm{~h}$ at room temperature. The oily residue was dissolved in a small volume of chloroform and transferred to a silica gel column (50 g). By elution with chloroform, containing an increasing amount of ethanol (from 0 to $8 \%$ ), two major fractions were obtained.

The fastest moving component, A, (45 mg) was recrystallized twice from ethyl acetate:petroleum ether to give colourless needles $(18 \mathrm{mg}), \mathrm{m} . \mathrm{p}$. $58-59^{\circ}$. (Found: $\mathrm{C}$ 43.91; $\mathrm{H}$ 6.89; $\mathrm{N}$ 7.22; $\mathrm{S}$ 33.27. Calc. for $\mathrm{C}_{7} \mathrm{H}_{19} \mathrm{NOS}_{2}$ : $\mathrm{C}$ 43.98: $\mathrm{H}$ 6.85; $\mathrm{N}$ 7.32; $\left.\mathrm{S} 33.55\right)$. $[\alpha]_{\mathrm{D}^{32}}-132^{\circ}$ (c 0.8, abs. EtOH); $\lambda_{\max }(\mathrm{EtOH}) 253 \mathrm{~nm}(\varepsilon 16000)$; IR (KBr): strong and characteristic bands at: $3450(\mathrm{NH}), 1560,1180$, and $1160 \mathrm{~cm}^{-1}$. The structure of the product as (-)-6-(2-methylthioethyl)-tetrahydro-1,3-oxazine-2-thione (IV) was further supported by the NMR-spectrum (100 MHz), exhibiting signals at $\delta 8.2$ (1H, NH), $4.5(1 \mathrm{H}, \mathrm{m},-\mathrm{CH}-\mathrm{O}), 3.4\left(2 \mathrm{H}\right.$, t, with fine structure, $\left.-\mathrm{CH}_{2}-\mathrm{CH}_{2}-\mathrm{NH}\right), 2.7(2 \mathrm{H}, \mathrm{t}$, $\left.-\mathrm{S}-\mathrm{CH}_{2}-\mathrm{CH}_{2}\right), 2.18(3 \mathrm{H}, \mathrm{s}, \mathrm{CH}-\mathrm{S}-)$, and $\mathrm{ca} .2 .0\left(4 \mathrm{H}, \mathrm{m},-\mathrm{S}-\mathrm{CH}_{2}-\mathrm{CH}-\right.$, and $-\mathrm{O}-\mathrm{CH}-\mathrm{CH}_{2}-\mathrm{CH}_{2}-\mathrm{N}-$ ). The mass spectrum showed a parent ion at $\mathrm{m} / \mathrm{e} 191$ and fragments corresponding to loss of $33(\mathrm{SH})$ and $47\left(\mathrm{CH}_{3} \mathrm{~S}\right)$ mass units; a strong peak at $m / e 61$ was attributable to the stable ion $\mathrm{CH}_{3} \mathrm{SCH}_{2}{ }^{+}$.

A slower moving fraction, (B), $(200 \mathrm{mg})$ was recrystallized from ethyl acetate: petroleum ether to give nacreous, colourless plates, m.p. 71-72 ${ }^{\circ}$ (Found: C 40.34; $\mathrm{H}$ 7.77; $\mathrm{N} 13.31 ; \mathrm{S} 30.56$. Calc. for $\mathrm{C}_{7} \mathrm{H}_{18} \mathrm{~N}_{2} \mathrm{OS}_{2}$ : C 40.38; $\mathrm{H}$ 7.75; $\left.\mathrm{N} 13.45 ; \mathrm{S} 30.80\right)$. $[\alpha]_{\mathrm{D}}{ }^{26}-15.7^{\circ}$ (c 1.6, abs.EtOH); $\lambda_{\max }(\mathrm{EtOH}) 243 \mathrm{~nm}(\varepsilon 11000)$; IR (KBr): strong bands at $3300,1640,1540$, and $1120 \mathrm{~cm}^{-1}$. The structure of the product as $(-)-1-(3-$ hydroxy-5-methylthiopentyl)-thiourea (V) was confirmed by the NMR-spectrum (in $\left.\left(\mathrm{CD}_{3}\right)_{2} \mathrm{SO}\right): \delta 7.5(1 \mathrm{H}, \mathrm{NH}), 6.9\left(2 \mathrm{H}, \mathrm{NH} \mathrm{H}_{2}\right), 4.5(1 \mathrm{H}, \mathrm{d}, \mathrm{OH}), 3.4\left(3 \mathrm{H}, \mathrm{m},-\mathrm{CH}_{2}-\mathrm{N}-\right.$, and $-\mathrm{CHOH}-), 2.5\left(2 \mathrm{H}, \mathrm{t},-\mathrm{S}-\mathrm{CH}_{2}-\right), 2.0\left(3 \mathrm{H}, \mathrm{s}, \mathrm{CH}_{\mathrm{s}} \mathrm{S}-\right)$, and $1.5(4 \mathrm{H}, \mathrm{m}$, $-\mathrm{S}-\mathrm{CH}_{2}-\mathrm{CH}_{2}-\mathrm{CHOH}-$, and $\left.-\mathrm{CHOH}-\mathrm{CH}_{2}-\mathrm{CH}_{2}-\mathrm{N}\right)$. The mass spectrum contained a molecular ion $(\mathrm{m} / \mathrm{e} 208)$, and fragment ions corresponding to losses of SH (33) and $\mathrm{CH}_{3} \mathrm{~S}(47)$; again, a strong $m / e 61$ ion $\left(\mathrm{CH}_{3} \mathrm{SCH}_{2}{ }^{+}\right)$was present.

(ii) The $200 \mathrm{mg}$ aliquot of fraction $2,[\alpha]_{\mathrm{D}^{25}}+\mathbf{1 4}^{\circ}$ (EtOH), was treated overnight in chloroform solution with a few drops of triethylamine. The solution was evaporated to dryness, redissolved in chloroform, and chromatographed on a silica gel column (10 g) with chloroform:ethanol gradients as the eluting solvent. A crystalline product was obtained and recrystallized from ethyl acetate:petroleum ether, m.p. $58^{\circ}$, slightly lower than but undepressed on admixture with the tetrahydro-oxazinethione (IV) described above. Coinciding IR-spectra further served to confirm the identity.

Fraction 3. The next $120 \mathrm{ml}$ of eluate constituted fraction 3. On evaporation, a colourless oil resulted $(155 \mathrm{mg})$, the mass spectrum of which suggested that it chiefly consisted of 5-methylsulphinylpentyl isothiocyanate (VIII, or the enantiomer).

To the chloroform solution was added aniline $(150 \mathrm{mg})$. Next day, the solution was concentrated, and anhydrous ether was added, causing the separation of colourless 
crystals, which were recrystallized twice from ethyl acetate, m.p. $122-123^{\circ},[\alpha]_{\mathrm{D}}{ }^{32}-57^{\circ}$ (c 1.7, EtOH). The identity of the product as (-)-1-(5-methylsulphinylpentyl)-3-phenylthiourea (VII) was established upon comparison with an authentic specimen (reported for this: $:^{3}$ m.p. $126-126.5^{\circ},[\alpha]_{D^{25}}-61.6^{\circ} \pm 2.5^{\circ}$ (c 2.14, 96 \% EtOH).

Fraction 4. This consisted of the subsequent $180 \mathrm{ml}$ of the eluate. On evaporation, a crystalline residue $(270 \mathrm{mg})$ was obtained. After recrystallization from ethyl acetate: petroleum ether, an analytical specimen $(184 \mathrm{mg})$ was obtained, m.p. $103^{\circ},[\alpha]_{\mathrm{D}}{ }^{27}+22^{\circ}$ (c 1.45, EtOAc). (Found: $\mathrm{C} 37.62 ; \mathrm{H} \mathrm{5.81;} \mathrm{N} \mathrm{5.84;} \mathrm{S} 28.65$. Calc. for $\mathrm{C}_{3} \mathrm{H}_{13} \mathrm{NO}_{3} \mathrm{~S}_{2}$ : C 37.67; H 5.87; N 6.28; S 28.71). $\lambda_{\max }(\mathrm{EtOH}) 244 \mathrm{~nm}(\varepsilon 900)$. The IR-spectrum (KBr) exhibited strong bands at $3500(\mathrm{OH}), 2130-2200$ (doublet, NCS), $1300\left(\mathrm{SO}_{2}\right), 1140\left(\mathrm{SO}_{2}\right)$, and $785 \mathrm{~cm}^{-1}$. The mass spectrum showed a molecular ion at $m / e 223$, and strong peaks at $m / e 125$ (formally corresponding to $\mathrm{CH}_{2}=\mathrm{CH}-\mathrm{CH}=\mathrm{CH}-\mathrm{CH}_{2}-\mathrm{NCS}^{+}$), and $m / e 72$ $\left(\mathrm{CH}_{2} \mathrm{NCS}^{+}\right.$) (vide infra). The NMR-spectrum contained signals at $\delta 4.0(1 \mathrm{H}, \mathrm{m}$, $\left.\mathrm{H}_{2} \mathrm{C}-\mathrm{CHOH}-\mathrm{CH}_{2}\right), 3.72\left(2 \mathrm{H}, \mathrm{t},-\mathrm{CH}_{2}-\mathrm{CH}_{2}-\mathrm{NCS}\right), 3.24\left(2 \mathrm{H}, \mathrm{t}, \mathrm{CH}_{2}-\mathrm{CH}_{2}-\mathrm{SO}_{2}-\right)$, $2.99\left(3 \mathrm{H}, \mathrm{s}, \mathrm{CH}_{3} \mathrm{SO}_{2}\right), 2.4(1 \mathrm{H}, \mathrm{d},-\mathrm{CH}-\mathrm{OH})$, and $1.7-2.2\left(4 \mathrm{H}, \mathrm{m},-\mathrm{CH}_{2}-\mathrm{CHOH}-\right.$ $\left.\mathrm{CH}_{2}-\right) \mathrm{ppm}$. The combined evidence suggests that the compound is $(+)-3-h_{y d r o x y}-5$. methylsulphonylpentyl isothiocyanate (XI).

In keeping herewith, (XI) underwent cyclization, as followed by UV-spectroscopy, when an alcoholic solution of the isothiocyanate $(65 \mathrm{mg})$ was treated with triethylamine at room temperature overnight. Evaporation to dryness afforded a crystalline residue $(47 \mathrm{mg})$ which was recrystallized twice from ethyl acetate to give an analytical specimen (21 mg), m.p. $143-144^{\circ},[\alpha]_{\mathrm{D}^{23}}-92^{\circ}$ (c 1.1, MeOH). (Found: C 37.80; H 5.95; $\mathrm{N} \mathrm{6.15;}$ $\mathrm{S} 28.26$; Calc. for $\mathrm{C}_{7} \mathrm{H}_{13} \mathrm{NO}_{3} \mathrm{~S}_{2}$ : C 37.67; $\mathrm{H} 5.87 ; \mathrm{N} 6.28 ; \mathrm{S} \mathrm{28.71)}$ ). $\lambda_{\max }(\mathrm{EtOH}) 252 \mathrm{~nm}$ $(\varepsilon 12300)$. The IR-spectrum (KBr) was devoid of NCS-absorption, but displayed strong bands at $3200(\mathrm{NH}), 1560, c a .1300\left(\mathrm{SO}_{2}\right), 1145\left(\mathrm{SO}_{2}\right), 1050$, and $795 \mathrm{~cm}^{-1}$. The mass spectrum was virtually identical with that of the corresponding isothiocyanate (XI), sug. gesting that the latter cyclized thermally in the inlet. The experimental evidence supports a formulation of the compound as (-)-6-(2-methylsulphonylethyl)-tetrahydro-1,3-oxazine-2. thione (X).

Attempts to produce a thiourea derivative of (XI) by treatment with methanolic ammonia resulted in isolation of the cyclized product (X). The mother liquors, according to chromatography, seemed to contain the linear thiourea, but no further attempts were made to obtain it in pure form.

Fraction 5. The last fraction, containing $68 \mathrm{mg}$ of solids in $250 \mathrm{ml}$ of eluent, emerged from the column only after prolonged elution with chloroform:ethanol (94:6). Since the composition, according to TLC, proved complex, no attempts were made to isolate the isothiocyanate fraction, but the solution was treated overnight, without further purification, with triethylamine, in order to bring about intramolecular cyclization. The residue $(70 \mathrm{mg})$ was dissolved in a few drops of chloroform and applied to a column, packed with alumina (neutral, $25 \mathrm{~g}$ ). Elution was performed with $75 \mathrm{ml}$ portions of chloroform, successively containing 1 and $2 \%$ of ethanol; $20 \mathrm{ml}$ fractions were collected. Fractions 5-11 were combined and evaporated to dryness. The residue was recrystallized twice from ethyl acetate in order to obtain an analytical specimen $(13 \mathrm{mg}), \mathrm{m} . \mathrm{p} .136-137^{\circ}$ (sintering from $\left.\left.120^{\circ}\right),[\alpha]_{\mathrm{D}}{ }^{28}-144^{\circ}(c) 1.0, \mathrm{EtOH}\right)$. (Found: C 38.23; H 6.86; N 6.21. Calc. for $\mathrm{C}_{7} \mathrm{H}_{13} \mathrm{NO}_{2} \mathrm{~S}_{2}, 0.5 \mathrm{H}_{2} \mathrm{O}$ : C 38.89; $\mathrm{H}$ 6.53; H 6.48). $\lambda_{\max }(\mathrm{EtOH}) 252 \mathrm{~nm}(\varepsilon 11300)$. The infra-red spectrum $(\mathrm{KBr})$ contained strong bands at 3400, 3200, $1640\left(\mathrm{H}_{2} \mathrm{O}\right), 1570$, 1178 , and $1020(\mathrm{~S}=\mathrm{O}) \mathrm{cm}^{-1}$, whereas the mass spectrum contained a molecular ion at $m / e$ 207, and ionic fragments corresponding to the losses of 17 and $63\left(\mathrm{CH}_{3} \mathrm{SO}\right)$ mass units. The combined evidence indicates that the isolated compound is (-)-6-(2-methylsulphinylethyl)-tetrahydro-1,3-oxazine-2-thione (XII). According to the mass spectrum it seems likely that the product is slightly contaminated with the corresponding sulphone (X) described above.

The authors are grateful to Professor R. Gmelin for his help and advice during the present investigation. The invaluable assistance of the Botanic Garden of the University of Copenhagen in the production of large seed quantities of $E$. hieracifolium is greatly appreciated. Thanks are due to Dr. S. Jacobsen for assistance with the mass spectra, and to Dr. C. Pedersen for help with the NMR-spectra.

Acta Chem. Scand. 24 (1970) No. 5 


\section{REFERENCES}

1. Gmelin, R., Kjær, A. and Schuster, A. In preparation.

2. Kjær, A., Larsen, I. and Gmelin, R. Acta Chem. Scand. 9 (1955) 1311.

3. Kjær, A. and Gmelin, R. Acta Chem. Scand. 10 (1956) 1100.

4. Kjær, A. and Jensen, R. B. Acta Chem. Scand. 12 (1958) 1746.

5. Cheung, K. K., Kjær, A. and Sim, G. A. Chem. Commun. 1965100.

6. Ettlinger, M. G. and Kjær, A. In Mabry, T. J., Alston, R. E. and Runeckles, V. C. Recent Advances in Phytochemistry, Appleton-Century-Crofts, New York 1968, p. 58.

7. Kjær, A. Fortschr. Chem. Org. Naturstoffe 18 (1960) 122.

8. Gmelin, R., Kjær, A. and Schuster, A. Acta Chem. Scand. 22 (1968) 2875.

9. Kjær, A. and Gmelin, R. Acta Chem. Scand. 11 (1957) 577.

10. Gmelin, R. and Kjær, A. Acta Chem. Scand. 23 (1969) 2548.

11. Favarger, C. Bull. Soc. Botan. Suisse 74 (1964) 5.

12. Kjær, A., Ohashi, M., Wilson, J. M. and Djerassi, C. Acta Chem. Scand. 17 (1963) 2143.

Received November 17, 1969. 